\title{
Complexo médico-industrial/financeiro: os lados epistemológico e axiológico da balança
}

\section{| ${ }^{1}$ André Luis Oliveira Mendonça, ${ }^{2}$ Kenneth Rochel Camargo Jr. I}

Resumo: Neste artigo, empreendemos uma análise sobre a temática atinente ao complexo médico-industrial (CMI) e complexo médico-financeiro (CMF), inspirados no referencial teórico dos science studies. Amiúde, a temática referente ao complexo médico-industrial/financeiro é abordada pelo viés da dicotomia entre interesses econômicos e valores sociais. Aqui, almejamos chamar a atenção para a necessidade de se levar em consideração os vários prismas da questão, uma vez que as referidas noçōes procuram nomear um tipo de fenômeno extremamente complexo. De modo a se obter uma avaliação simultaneamente ampla e profunda do problema, julgamos ser oportuno desencavar o ideário subjacente tanto aos seus aspectos epistemológicos quanto aos axiológicos. Para realizar esse objetivo a contento, começamos com uma breve contextualização e reavaliação dos science studies; em seguida, realizamos uma espécie de revisão da literatura em português relativa ao conceito de CMI e CMF, chamando a atenção para as recentes tentativas de suplantar a dicotomia "interesses econômicos x valores sociais"; depois disso, procuramos deslindar, a partir da discussão acerca dos modos de produção do conhecimento, o background epistemológico e econômico subjacente a CMI; na sequência, colocamos em relevo alguns diagnósticos críticos da indústria farmacêutica, tendo como mote as noções de medicalização social e de medicina alternativa e complementar (MAC); por fim, apontamos na direção de uma abordagem a mais ampla e aguda possível de uma problemática que não pode mais ser pensada em moldes meramente dicotômicos.

\author{
1 Doutor em Filosofia pela \\ UERJ. Pós-doutorando do IMS/ \\ UERJ. Endereço eletrônico: \\ alomendonca@gmail.com \\ 2 Doutor em Saúde Coletiva pela \\ UERJ, com pós-doutorado no \\ Department of Social Studies of \\ Medicine da McGill University, \\ Canada. Professor Adjunto - \\ IMS/UERJ. Endereço eletrônico: \\ kencamargo@gmail.com
}




\section{Introdução}

Embora seja uma temática recorrente nas análises sobre o setor da saúde, a noção de complexo médico-industrial (CMI) ou complexo médico-financeiro (CMF) carece ainda de uma abordagem que possa dar cabo de toda a amplitude que o problema exige. Conquanto essa questão seja investigada, geralmente, pelo viés de um antagonismo entre interesses econômicos e valores sociais, começam a despontar autores que visam justamente à superação dessa cisão no interior dos CMI e CMF. Nosso intuito, aqui, consiste em reconstruir as controvérsias gravitando em torno das referidas noções, tendo como horizonte de análise o contexto brasileiro, sem que deixemos de nos reportar às análises dirigidas ao âmbito de outros países. Para tanto, escolhemos como referencial teórico um tipo de abordagem ainda relativamente pouco difundida na saúde coletiva brasileira, qual seja: os science studies. ${ }^{1}$ Dentre outras contribuições importantes, seus representantes procuram atribuir o mesmo peso aos aspectos axiológicos - compreendidos aqui de modo bem lato, indo dos interesses econômicos aos valores éticos - e às razões epistemológicas envolvidas nas práticas cognitivas. Ademais, ao reconstruírem as controvérsias científicas, eles visam a ancorarse em uma abordagem pretensamente simétrica (balança equilibrada entre os lados epistemológico e axiológico) para analisar tantos os "vencedores" quanto os "perdedores" de uma disputa. Por isso, também não proferimos, aqui, nenhum tipo de julgamento prévio acerca dos diversos posicionamentos frente ao problema de CMI e CMF, a não ser a sugestão de que falta aos analistas justamente a atitude de levar em consideração toda a complexidade que eles englobam.

Inspirados na modalidade de estudos realizados pelos praticantes dos science studies, buscamos olhar para o tema do complexo médico-industrial/financeiro sob vários prismas, o que fez com que esse artigo tenha adquirido um caráter notadamente programático. Mais precisamente, começamos com uma breve contextualização dos science studies, tendo em vista, mais do que meramente apresentar o nosso principal referencial teórico, tecer alguns comentários críticos que nos permitam aprimorar o seu enfoque originário; em seguida, realizamos uma espécie de revisão da literatura em português relativa ao conceito de CMI e CMF, chamando a atenção para as recentes tentativas de suplantar a dicotomia "interesses econômicos x valores sociais"; depois disso, procuramos deslindar o background epistemológico e econômico - mais precisamente, reportamo- 
nos aos chamados modos de produção do conhecimento atrelados às políticas de Ciência, Tecnologia e Inovação (CT\&I) - subjacente ao discurso daqueles que veem no chamado complexo econômico da saúde uma alternativa para o desenvolvimentismo; na sequência, colocamos em relevo alguns diagnósticos críticos da indústria farmacêutica, tendo como mote as noções de medicalização social e de medicina alternativa e complementar (MAC); por fim, apontamos na direção de uma abordagem a mais ampla, bem como a mais aprofundada possível, de uma problemática que precisa ser pensada para além da visão dicotômica.

\section{O consenso subjacente aos estudos de controvérsia: contextualizando os science studies}

A partir dos anos 1970, especialmente no contexto anglo-saxão, as análises de controvérsias surgiram como uma proposta alternativa aos estudos sobre ciência empreendidos até aquele momento. Na nossa interpretação, a emergência dessas análises significou uma "evolução natural" da então chamada nova filosofia da ciência, capitaneada por autores como Kuhn, Feyerabend, Lakatos, Toulmin, entre outros, que se insurgiram contra a epistemologia de inspiração positivista predominante. ${ }^{2}$ Sobremaneira, Kuhn (1962 [1978]) e Feyerabend (1975 [2007]) dirigiram ataques certeiros ao coração do corpo doutrinário positivista, cuja marca era a ênfase no componente lógico-linguísitico das teorias científicas. Em seu lugar, eles destacaram a relevância da história da ciência para uma apreensão mais fidedigna do conhecimento científico, tendo produzido, consequentemente, uma imagem de ciência distinta da concepção herdada, dando origem ao que se tornou conhecido como uma filosofia histórica da ciência, a qual encontra ecos ainda hoje nos trabalhos de Laudan e Hacking, para citar apenas dois dos mais influentes filósofos da ciência contemporâneos. Seu pressuposto basilar era o de que deveríamos livrar-nos da historiografia de inclinação whig, para a qual as teorias atuais seriam um aperfeiçoamento ou uma ampliação das teorias antigas, e adotarmos, ao invés disso, a historiografia prig que avalia as teorias obsoletas em seus próprios termos. Emblemática, nesse sentido, foi a proposta de Kuhn, segundo a qual, por exemplo, na querela entre Lavoisier e Priestley, não se deveria tomar partido do primeiro por ele ter se sagrado vitorioso com a defesa da existência do oxigênio, pois Priestley não teria agido de forma irracional pelo simples fato de, retrospectivamente, ser visto como fracassado; ele apenas endossava outros 
critérios epistêmicos incomensuráveis com os de Lavoisier. Tal tese, conhecida como incomensurabilidade entre referenciais teóricos (paradigmas) distintos, suscitou várias críticas e acusações de relativismo, endereçadas tanto a Kuhn quanto a Feyerabend, tendo o primeiro procurado atenuar suas asserçōes originais (especialmente, 1989; 2000) e o segundo, radicalizado na direção das suas consequências ético-políticas (notadamente, 1978; 1987; 1999). ${ }^{3}$

Decerto, influenciados pelas ideias aludidas acima, os formuladores do Programa Forte, especialmente Barnes (1974) e Bloor (1976 [1991]), cada um ao seu modo, sustentaram a tese de que a metodologia adequada para investigar as disputas científicas seria aquela que pautasse suas análises partindo de um ponto de vista o menos comprometido possível. Desde aquela época até nossos dias, Bloor (2007) continua defendendo, com veemência, a plausibilidade e consistência dos quatro princípios metodológicos do seu programa (causalidade, simetria, imparcialidade e reflexividade), que, apesar de inspiradores de muitos estudos levados a cabo pelos scholars dos science studies, sofreram várias reformulações posteriores. Com o fito de fazer jus às verdadeiras intenções dos programadores fortes, devemos ressaltar que, contrariamente às interpretaçôes de acordo com as quais estariam preocupados em desbancar sua autoridade cultural e política dentro das sociedades ocidentais, eles pretenderam erigir um tipo de abordagem naturalista da ciência, apenas colocando a sociologia como substituta da filosofia em sua clássica pretensão de explicar o conteúdo cognitivo da ciência. ${ }^{4}$ Daí viria justamente o epíteto "forte" do programa, pois não mais se trataria de uma sociologia do conhecimento científico (SSK), que vai de Mannheim a Merton e Ben-David, preocupada em se ater exclusivamente aos "fatores externos" responsáveis pelos "erros" e "desvios" da "boa ciência”, ou atenta tão-somente aos aspectos institucionais da ciência e ao seu contexto de descoberta: agora a sociologia seria capaz de explicar erro e acerto, bem como verdade e falsidade, uma vez que todo conhecimento teria uma natureza social, isto é, os fatos científicos seriam socialmente construídos. 5 Em outras palavras, e para permanecer no exemplo mencionado, as teorias de Lavoisier e de Priestley deveriam ser abordadas de modo simétrico, porquanto ambas possuiriam o mesmo tipo de causalidade, qual seja, o contexto social em que estavam embebidas.

Após a consolidação das análises de controvérsias na década de 1970, devido aos trabalhos de autores do porte de um Collins, atualmente desenvolvendo 
interessantes estudos de cunho teórico e empírico sobre seu conceito de interactional expertise, uma nova geração de scholars despontou ao final da referida década e começo dos anos 1980, na qual sobressaem Latour, KnnorCetina, Galison, Shapin, Daston, Pickering e Lenoir; todos praticantes dos science studies (designação que engloba uma multiplicidade de vertentes), mais afeitos às abordagens enquadradas na sigla STS, cujo traço distintivo consiste em investigar a ciência, por meio de uma perspectiva interdisciplinar, como uma prática local levada a termo normalmente nos laboratórios. Mendonça (2008) procurou mostrar a persistência de uma relação desequilibrada entre as principais disciplinas utilizadas nos estudos sobre as ciências naturais: se, na tradição positivista, o peso pendia para a filosofia da ciência e, no programa forte, para a sociologia, mais recentemente a preponderância recaiu sobre a história da ciência em detrimento das demais. ${ }^{6}$ Daí a necessidade de voltar o olhar para autores contemporâneos (nomeadamente, Hacking, Rouse, Fine e Fuller, entre outros) que possam contribuir com estudos empiricos mais filosoficamente consistentes. Preenchida essa lacuna, os science studies podem ser de grande valia, não apenas como inspiração metodológica, mas também por suas novas imagens de ciência, nas quais emerge uma paisagem muito mais complexa e rica do que dispúnhamos antes: ela é uma produção circunscrita aos contextos geográfico e histórico específicos (o que não quer dizer que seus "produtos" não possam ser estandardizados e, por conseguinte, incorporados em outros locais e épocas); é uma produção material, e não apenas etérea, para empregar a expressão de Galison (a ciência formula teorias e constrói fatos, mas também artefatos tecnológicos); ela é uma construção social (cai por terra a epistemologia centrada no cientista isolado, a descobrir a "verdade", formulando teorias independentemente do seu entorno); e assim por diante.

Mendonça (2008) apontou também uma assimetria persistente entre o axiológico e o epistemológico. Ao contrário da visão corrente de que os praticantes dos science studies seriam detratores da racionalidade e objetividade científicas ${ }^{8}$, praticamente todos os autores supracitados tendem a propagar a ideia, ainda que sub-repticiamente, de que as ciências ocupam (ou devem ocupar?) um papel prevalecente nas sociedades ocidentais. Ademais, apesar de sua imagem de ciência ser bem mais matizada que as antecedentes, esses estudiosos acabam reificando o contexto social mais amplo, como se as sociedades fossem sempre estáticas e 
fechadas. ' Não obstante essas falhas e deficiências, o fato é que esses estudos de caso sobre a ciência tornaram muito claro que, historicamente, ciência e sociedade sempre se misturaram. No diagnóstico de Latour (1994), por exemplo, “jamais fomos modernos", conquanto se saiba que ele queira, no seu prognóstico, propor uma espécie de neo-modernidade (2001; 2004). Dessarte, ao tratar questôes epistemológicas juntamente com questôes axiológicas, sem dúvida, os science studies, com os devidos aprimoramentos aqui indicados, servem como um oportuno referencial para perscrutar a área da saúde, tanto por seus métodos empregados, quanto por sua concepção bem mais robusta de ciência.

\section{Uma breve história do conceito de CMI: da denúncia ao endosso}

O que não constitui um mero trocadilho, a expressão "complexo médicoindustrial", ou "complexo médico-financeiro", nomeia um conceito realmente complexo: ele envolve uma gama de elementos, especialmente o setor produtivo industrial de base química e biológica (fármacos, vacinas e hemoderivados etc.) e de base mecânica, eletrônica e de materiais (equipamentos mecânicos, equipamentos eletro-eletrônicos, próteses etc), bem como o setor de prestação de serviços (hospitais, ambulatórios e serviços de diagnósticos e de tratamento); sem contar o fato de abarcar um conjunto grande de atores: incluindo de médicos e enfermeiros até aqueles ("pacientes") que demandam pelos seus serviços, passando por gestores, pesquisadores, trabalhadores de várias áreas, entre outros.

Cunhada em solo anglo-saxão nos $1970,{ }^{10}$ a expressão foi certamente inspirada no termo "complexo militar-industrial", correntemente empregado já desde os anos 1960 - especialmente no contexto norte-americano. ${ }^{11} \mathrm{O}$ complexo militar-industrial, sem dúvida alguma, pode ser considerado como um dos grandes responsáveis por impulsionar o modo de produção de conhecimento conhecido como big science, na qual se dá justamente a utilização de recursos materiais e humanos em grande escala, tendo em vista a obtenção de resultados amiúde relativos a interesses econômicos, embora a aquisição de conhecimento propriamente dito também seja um motor importante do processo. Galison (1992), por exemplo, evidencia a relação que a física de partículas manteve - e mantém - com a Defesa dos EUA, sem cair no "denuncismo". No caso específico do complexo médico-industrial, a questão premente que se coloca é a seguinte: 
como levar em conta a lógica econômica em um setor que deveria se pautar pelo atendimento das necessidades das pessoas, por intermédio de uma prestação de serviços de qualidade, de modo integralizado e universalizado?

Cordeiro (1980) é a referência pioneira no Brasil na utilização do conceito de CMI. Seu objetivo primordial consistiu em pensar a inter-relação entre a lógica (econômica) da produção de bens e a lógica (social) da prestação de serviços na área da saúde. Mais precisamente, valendo-se especialmente do arcabouço teórico da tradição marxista, ele procurou analisar a questão do consumo de medicamentos, sem ter deixado de lado os problemas relacionados à sua produção e circulação, tampouco às mudanças sofridas pela prática médica diante do então novo quadro de medicalização da sociedade. Quiçá antevendo uma situação que se agravaria nas décadas seguintes, ele chamava a atenção para a diminuição do poder da intervenção médica, face às estratégias de medicalização arquitetadas pela indústria farmacêutica, que contava com uma certa conivência do Estado. Para conter essa tendência, seria preciso desmascarar as ideologias que escondem as condições sociais de produção do consumo, e contar com novas conquistas no plano das políticas de saúde e medicamentos, atreladas às reivindicaçôes e lutas sociais mais amplas, dentre as quais, naquela época, destacava-se a busca da retomada do processo democrático interrompido pelo golpe militar de 1964. Ao fim e ao cabo, ao menos naquele momento, Cordeiro procurava desnudar os interesses econômicos por trás das indústrias farmacêuticas, e, principalmente, mostrar como o desenvolvimento capitalista era determinado pelas práticas políticas das classes sociais. Subjacente a esse contexto está o embate de décadas, no Brasil e no mundo, sobre como atender às demandas de atenção à saúde, com um lado do campo defendendo soluções de mercado, e o outro, saídas a partir do Estado. Essa tensão se agudiza durante o regime militar e a luta pela ampliação do papel do Estado - o que define ao menos parcialmente o chamado Movimento de Reforma Sanitária se une à luta pela redemocratização. A entronização da saúde como direito na nova constituição pode ser vista como vitória do segundo grupo, mas sua implementação plena continua sendo uma luta contra a lógica dita "privatista". ${ }^{12}$

Após uma esclarecedora revisão da literatura em torno do conceito de CMI, Andreazzi e Kornis (2008, p. 1418) constatam a exacerbação de um dos receios de Cordeiro, justamente com a formação de um complexo médico-financeiro:

Sucessivas estratégias de transformação dos modelos de prestação do cuidado a partir do questionamento das necessidades de consumo criadas pela indústria são contraba- 

de serviços de saúde, inclusive através da subsunção das evidências médicas ao interesse das grandes empresas.

Tomando a noção de complexo médico-industrial emprestada e cunhando a de complexo médico financeiro, Vianna $(1994 ; 2002)$ manteve uma postura distinta da de Cordeiro, tendo incorporado novos referenciais teóricos e novos problemas às suas análises, talvez até por se tratar de um outro momento histórico. $\mathrm{Na}$ realidade, a própria posição de Vianna modificou-se (talvez em grau, não em gênero) com o tempo, quiçá em função das novas vicissitudes: se, em seu texto de 1994, Vianna concluiu sua reconstrução da chamada década perdida (anos 1980), que teria sido paradoxal com perdas e ganhos, com um ligeiro lamento a respeito da queda na produção das indústrias farmacêuticas, bem como nas de insumos e equipamentos por conta do Governo Collor, no trabalho de 2002 seu tom parece ser o de grave preocupação diante de uma nova realidade: o advento de um complexo médico-financeiro, no qual o capital financeiro procura tornar-se hegemônico por meio de um papel regulatório, a ser desempenhado pelas chamadas empresas de managed care. Seu receio implícito parece ser o de que esta transformação, observada originalmente nos EUA, possa ocorrer também na assistência à saúde do Brasil, contrariando as diretrizes básicas do SUS. Em última análise, tratar-se-ia da lógica neoliberal adentrando o setor saúde, que engloba dentro de si diversos atores, representados nas figuras do Estado e das suas instituições públicas e privadas prestadoras de serviços, das indústrias farmacêuticas, de equipamentos e de insumos, e, agora, das empresas financeiras. Vianna observa que, apesar de ainda não ter ocorrido uma substituição completa de um tipo de complexo por outro - ainda estaríamos em um período de embate entre os setores industrial e financeiro por hegemonia -, já podemos perceber as principais modificações e diferenças: no CMF, a tecnologia tornou-se intensiva, ao passo que era extensiva em CMI; os gastos e investimentos estão decrescendo no CMF, enquanto eram crescentes em CMI; a administração era pautada pelo planejamento em CMI, mas agora é conduzida pelo managed care; por fim, como as siglas já sugerem, a hegemonia era da indústria e, agora, das finanças. A proposta do autor é que o Estado atue como regulador e gestor nesse contexto realmente complexo e conflituoso. Vale dizer que a discussão acerca da tecnologia e da noção de inovação que lhe é atrelada também ocupam um lugar de destaque na análise. ${ }^{13}$ 
Cônscios da necessidade de se obter uma "radiografia" da estrutura e dinâmica da saúde no Brasil - no caso, referente aos anos 1990 -, para se poder produzir um prognóstico adequado de modo a sanar suas mazelas, os trabalhos publicados na coletânea organizada por Negri e Di Giovanni (2001) apontam na direção de uma tentativa de superação da dicotomia entre a lógica sanitária e a lógica econômica. O próprio título da introdução, assinada por Braga e por Silva, já é bastante sugestivo: "A mercantilização admissível e as políticas públicas inadiáveis". $\mathrm{Na}$ década de 1990, teria ocorrido uma radicalização do processo de capitalização da saúde, no qual o Estado ainda desempenhava um papel preponderante, passando a viger uma mercantilização conduzida sob a égide do setor privado, a que, quando é de qualidade, poucos têm acesso. Como tentativa de soluçãa, os autores propõem, após indicarem as reformas necessárias, o retorno de uma função regulatória bastante forte do Estado, com uma "atuação governamental em toda a 'cadeia produtiva' do setor saúde” (p. 21). Na primeira parte do livro, que é mais diretamente relacionada ao complexo médico-industrial, praticamente todos os autores sugerem a necessidade de o Brasil se tornar mais independente, tanto na produção de medicamentos quanto de materiais e equipamentos médicos.

Seguindo na mesma direção indicada acima, porém de modo independente, Gadelha $(2003$; 2006) pretende ultrapassar a divisão dicotômica entre os princípios sociais da saúde e os interesses econômicos do capital. Alegando-se ancorado no referencial marxista e, ao mesmo tempo, na obra de Schumpeter, ele visa retomar o projeto desenvolvimentista da tradição cepalina (especialmente, a perspectiva estruturalista de Furtado), sendo que com ênfase no processo de inovação tecnológica. $\mathrm{Na}$ sua avaliação, a separação das lógicas sanitária e capitalista leva os que lutam pela implementação dos princípios de universalidade, equidade e integralidade a atuar, paradoxalmente, em prol do indesejável neoliberalismo (modelo que tenta justamente impedir o desenvolvimento dos países periféricos), uma vez que não atentam para o desenvolvimento baseado em inovação, determinante na chamada sociedade do conhecimento:

Assim, observa-se um duplo e contraditório ataque [do modelo neoliberal e do pensamento crítico sanitário] para a inovação em saúde vinculada ao desenvolvimento das forças produtivas dos setores industriais (GADELHA, 2006: 15).

Com base em dados levantados pela Pesquisa Industrial de Inovação Tecnológica (PINTEC), de 2003, e pelo IBGE, de 2005, os quais evidenciam 
ainda um baixo padrão de inovação tanto nas indústrias de base química e biotecnológica e indústrias de base mecânica, eletrônica e de materiais, quanto nos setores de prestação de serviços (hospitais, ambulatórios e serviços de diagnóstico e tratamento), Gadelha enxerga uma luz no fim do túnel, ao apontar a recente implementação de políticas públicas e a criação de novas instituições, como a Política Industrial Tecnológica e de Comércio Exterior (PITCE), o Programa de Apoio de Desenvolvimento da Cadeia Produtiva Farmacêutica (Profarma), a Agência Brasileira de Desenvolvimento Industrial (ABDI) e a Secretaria Nacional de Ciência, Tecnologia e Insumos Estratégicos, apesar de julgar que muitos esforços ainda precisam ser concentrados para a articulação consistente de uma política nacionalista industrial com uma política de saúde fundada na dinâmica da inovação, no desenvolvimento e na inclusão social..$^{14}$

\section{Contextos epistemológico e político-econômico de CMI e CMF: CT\&I e desenvolvimentismo}

Desde pelo menos o século XVIII, no contexto dos países desenvolvidos, a produção de conhecimento científico e tecnológico vem sendo identificada como um fator determinante para o crescimento econômico e a emancipação social. Com efeito, os setores de Ciência e Tecnologia (C\&T) e Pesquisa e Desenvolvimento (P\&D) recebem cada vez mais recursos do PIB dos países com pretensões desenvolvimentistas, já que são vistos como estratégicos para alavancar o progresso. No caso específico do Brasil, com 25 anos de atuação, o Ministério de Ciência e Tecnologia vem consolidando C\&T como política de Estado. ${ }^{15}$ Obviamente, nessa nova configuração, o setor de saúde acaba ocupando um lugar de destaque. ${ }^{16}$ Sem precisarmos entrar aqui nos meandros da política científica adotada pelo MCT, passamos a discorrer, em linhas bens gerais, sobre as concepções de produção do conhecimento que lhes parece servir de alicerce, visto que aí reside também o pano de fundo onde atua o complexo médico-industrial/financeiro.

Apesar de a temática adstrita aos modos de produção do conhecimento ter começado a ocupar um lugar de destaque nas análises apenas recentemente, sua relevância já havia sido notada pelo menos desde a segunda metade do século XX. O cientista e filósofo da ciência Polanyi, por exemplo, já sugeria, nos idos de 1962, que 
a comunidade de cientistas é organizada em um modo que se assemelha a certos tra-

ços de um corpo político e funciona de acordo com princípios econômicos similares àqueles pelos quais a produção de bens materiais é regulada. (2000, p.1)

No seu caso em particular, ele abria o seu texto com essa afirmação (talvez bombástica na época) para, logo em seguida, fechar com a ideia mais tradicional da necessidade de a comunidade científica ser moldada por uma cooperação livre entre os cientistas, sem nenhum tipo de restrição externa, pois somente uma ciência autônoma em relação aos interesses da sociedade poderia progredir efetivamente. De todo modo, o que nos interessa aqui é o fato de que o seu pressuposto segundo o qual a "República da Ciência" possui aspectos econômicos e políticos, ainda que internos à própria comunidade científica, acabou servindo como uma antecipação, senão dos modelos de gestão propriamente ditos, ao menos da reconhecida necessidade de se discuti-los de um modo mais explícito.

Mais recentemente, o debate gravitando em torno da forma como a produção do conhecimento é (ou deve ser) conduzida foi renovado pela publicação de um livro que suscitou várias polêmicas ${ }^{17}$, a saber: The New Production of Knowledge: The Dynamics of Science and Research in Contemporary Societies. Fruto de um trabalho coletivo (Michael Gibbons, Camille Limoges, Helga Nowotny, Simon Schwartzman, Peter Scott e Martin Trow), sua tese norteadora consiste na afirmação de acordo com a qual estaria ocorrendo uma grande mudança na produção do conhecimento, uma vez que o "Modo 1" (conhecimento desinteressado, fundamental, básico ou puro) teria deixado de ser predominante - até mesmo nas universidades e institutos de pesquisa - e cedido o espaço para o chamado "Modo 2" (conhecimento que ora tenta atender às demandas sociais, ora se deixa levar por interesses econômicos). ${ }^{18}$ Embora muitos problemas já estivessem "no ar" na ocasiāo em que o livro surgiu, os autores tiveram o mérito de sintetizá-los de uma forma oportuna. Dentre as questôes levantadas como nevrálgicas desse novo corpo social da ciência, algumas permanecem problemáticas em termos do debate teórico: como decidir sobre as prioridades de pesquisa; qual a linha que separa a "pesquisa engajada" da comercialização da pesquisa; de que modo resolver a tensão entre a ideia da ciência como conhecimento público e o direito de propriedade intelectual; como escolher, adequadamente, o melhor modelo de gestão do conhecimento; e o que fazer para evitar que os mecanismos de avaliação do desempenho dos pesquisadores sejam injustos. 
Com relação ao diagnóstico feito sobre o "Modo 2", os pontos destacados foram os seguintes: 1-o conhecimento passou a ser gerado dentro de um contexto de aplicação (social); 2- a transdiciplinaridade tornou-se uma das características principais da produção de conhecimento; 3- há muito mais diversidade, tanto dos locais nos quais o ele é produzido quanto dos tipos de que são produzidos, incluindo as novas tecnologias de comunicação e informação; 4- a nova produção do conhecimento alcançou um nível mais alto de reflexividade; 5 - o chamado "controle de qualidade" adquiriu novas formas de avaliar a produção do conhecimento.

Além disso, os autores também procuraram indicar os contextos concretos de desenvolvimento do "Modo 2", que, para eles, viriam a ser: 1- o de comercialização da pesquisa; 2- o de massificação (democratização) da educação de nível superior; 3- o do novo papel das humanidades (engajamento e reflexividade); 4- o da globalização; 5- o da capacidade de reconfiguração das instituições; e 6- o da relevância da gestão. Diante desse quadro, uma enorme quantidade de indagações foi despertada ${ }^{19}$, a começar pela própria validade ou acuidade do diagnóstico feito por Gibbons e cia., ou pela aprovação (sub-reptícia) do "Modo 2".

Contrapondo-se a este, Etzkowitz e Leydesdorff (1995; 2000) formularam um modelo alternativo de produção e gestão do conhecimento denominado de "Tripla Hélice", cuja ideia básica, como a própria expressão sugere, é a de que o modelo ideal de produção de conhecimento possuiria três vértices fundamentais: a academia, a indústria e o governo. Trata-se de um modelo, embora teorizado pelos autores somente a partir de meados dos anos 1990, provavelmente posto em prática a mais tempo do que normalmente se supõe, ao menos nos países considerados desenvolvidos e em vias de desenvolvimento, tal como o Brasil. ${ }^{20}$ Obviamente, por incluir um novo ator - no caso, o setor produtivo - no contexto de construção do conhecimento, essa modalidade de produção da ciência e tecnologia acaba gerando a repulsa de um número considerável de pesquisadores, que se sentem ameaçados com a possibilidade de o conhecimento se tornar uma espécie de refém do interesse privado de alguns empresários. Uma vez operando com lógicas completamente diferentes entre si - assim defendem muitos pesquisadores dos mais variados campos -, empresários, pesquisadores e políticos não deveriam fazer parte de um mesmo arranjo institucional. Do lado daqueles que defendem o estreitamento dos laços entre as três esferas, podemos mencionar o caso do filósofo e historiador da ciência Timothy Lenoir, que forneceu o exemplo da Universidade 
de Stanford situada no famoso Vale do Silício como sendo paradigmática da união bem-sucedida entre universidades, empresas e governos:

A chave para entender esses fluxos dinâmicos entre o Vale e Stanford é o papel do
apoio financeiro dado pelo governo federal à pesquisa e ao desenvolvimento em uni-
versidades importantes, bem como o estímulo dado pela pesquisa e desenvolvimento
federal à indústria em regiōes de tecnologia como o Vale do Silício. Stanford contri-
buiu para múltiplas ondas de inovação no Vale do Silício, concentrando-se, de manei-
ra bem-sucedida, na obtenção de financiamento federal para pesquisa científica que
seja, ao mesmo tempo, industrialmente relevante. Criar e manter uma cultura empre-
endedora tem sido crucial para desenvolver esse feedback sinergístico entre a pesquisa
financiada com verbas do governo federal e os problemas de pesquisa da indústria,
e deu aos pesquisadores de Stanford condiçôes de obter avanços significativos na ci-
ência e na engenharia. Esse é o resultado surpreendente do nosso estudo: a atividade
empreendedora de Stanford é efetivamente uma fonte importante de novos campos
científicos, que aumentam a capacidade de seu corpo docente de ser competitivo para
obter prêmios pela pesquisa. (LENOIR, 2005: 240).

Contudo, prossegue a retórica dos defensores da aproximação entre instituições acadêmicas, empresas e governo. Não basta apenas produzir fatos científicos e artefatos tecnológicos para o casamento feliz do conhecimento com as demais esferas de valores humanos: é preciso apostar nas e realizar inovações. De fato, no interior do arcabouço teórico e político de C\&T, a noção de inovação passou a exercer um papel preponderante. Costuma-se apontar o economista Joseph Schumpeter como sendo um dos primeiros grandes teóricos da inovação com uma conotação acentuadamente econômica. Mesmo ainda na primeira metade do século XX, Schumpeter já punha em relevo a capacidade e inovação técnicas como elementos primordiais para o desenvolvimento econômico e a acumulação de capital. Mais recentemente, despontaram vários teóricos que, por reformularem o pensamento do mestre, receberam, ou eles próprios passaram a adotar, a designação genérica de evolucionistas ou neo-schumpeterianos; dentre os quais ocupam um posto de destaque Richard Nelson, Nathan Rosenberg, Sidney Winter, Giovanni Dosi e Joseph Stiglitz. ${ }^{21}$

À guisa de curiosidade, vale a pena mencionar alguns dos temas abordados (sempre com o emprego de uma metodologia multidisciplinar e, geralmente, a partir do estudo de casos concretos) dentro dessa perspectiva: os padrões de mudança tecnológica das economias de natureza capitalista, bem como das inovaçôes tecnológicas "revolucionárias", enfocando como elas são apropriadas pelas empresas e em quais países elas acontecem; a mudança tecnológica como 
geradora do crescimento e as instituições sociais que a moldam; o progresso e a inovação técnicos como variáveis condicionantes do desenvolvimento, tanto no âmbito específico das empresas quanto no da esfera econômica mais ampla; a competição por meio da inovação tecnológica e da diferenciação de produtos; a necessidade de pesquisas tecnológicas para as empresas que almejam o seu crescimento; informação, apropriação e geração de inovação; relações entre inovação tecnológica, exportação e desenvolvimento. Eis uma ampla lista com variações sobre um mesmo tema: a inovação como mola propulsora do progresso econômico - seja das empresas, seja dos países. ${ }^{22}$

Normalmente, os neo-schumpeterianos são identificados como os grandes mentores teóricos do neoliberalismo (mais precisamente, das políticas científicas neoliberais), o que não deixa de ser o caso se nos detivermos apenas à sua produção intelectual originária. De fato, em seus primeiros trabalhos, esses autores carregavam a tinta no uso de palavras como "mercado", "setor privado", "livre iniciativa", "lucratividade", etc, o que parece, entretanto, não mais ocorrer, ao menos na mesma medida, em suas teses mais recentes. Em um trabalho conjunto (nas palavras dos próprios autores, trata-se de uma “introdução às contribuições da força-tarefa sobre 'Políticas Industriais e Desenvolvimento, Iniciativa para o Diálogo sobre Políticas””), por exemplo, Dosi, Nelson e Stiglitz, juntamente com Mario Cimoli, defendem a tese segundo a qual há necessidade de as instituiçôes e políticas públicas voltarem a ser protagonistas na construção dos chamados sistemas nacionais de produção e inovação, organizando e regulando os "mercados sempre imperfeitos". É como se estivessem "profetizando" sobre a necessidade de se criar uma nova ordem política e econômica, dados os impasses gerados pelo atual neoliberalismo imperante; ou, para ser mais exato, chegouse à conclusão de que a saúde do mercado não pode prescindir dos cuidados do Estado, e que um mercado forte e saudável pode (deve?) contribuir com melhorias do grande corpo social:

Chegou o momento de construir um 'novo consenso' sobre todas essas questōes, um consenso que tenha como característica proeminente a exploração de formas de governança institucional que também fomentem a acumulação de conhecimentos nos países em desenvolvimento e que tornem sua exploração econômica eficiente e consistente com os múltiplos interesses de seus agentes motivados pelo lucro. Sugerimos que um tal 'consenso' seja baseado numa visão pragmática dos mercados, por meio da qual estes possam às vezes funcionar num sentido 'desenvolvimentista', e outras vezes não. E, mesmo quando eles funcionam, que sua efetividade não seja separada das contribuiçõos 
de instituições e políticas de fomento. E, last but nos least, esse consenso deverá ser sensível a questões de equidade e de acesso à repartição dos benefícios do crescimento decorrentes do aprendizado organizacional e tecnológico. (CIMOLI et al., 2007, p. 80)

Obviamente, há toda uma constelação de autores que continuam analisando CT\&I sob a égide do referencial teórico de inspiração marxista, contrapondose, assim, às análises mencionadas. Sem poder aqui esmiuçar as propostas dessa vertente, cabe apenas mencionar que, em vez de se colocar ênfase, pura e simplesmente, na ideia de inovação tecnológica como mola para o progresso econômico, busca-se repensar a noção de inovação em uma perspectiva mais social. Sobre a proposta de inovação em termos sociais no contexto brasileiro, vale ressaltar os trabalhos de Baumgarten (2005) e de Lianza e Addor (2005).

No caso específico do setor saúde, estudos tais como o de Conde e AraújoJorge (2003) sugerem que o conceito de inovação empregado pelos gestores em saúde costuma ser compreendido quase exclusivamente em sua acepção tecnológica, com praticamente nenhuma referência ao seu sentido social, como o de inovação em termos de serviços. ${ }^{23}$

\section{Radiografando o estado de saúde (convalescente?) de $\mathrm{CMI} / \mathrm{CMF}$}

Contrapondo-se aos analistas que vislumbram no setor de saúde uma oportunidade estratégica de reunir as esferas econômica e social, não é incomum a postura crítica diante da indústria farmacêutica. Emblemática nesse sentido é a denúncia, fundamentada em dados concretos, levada a cabo por Angell (2005), que tomou a situação da área da saúde norte-americana e também europeia para empreender suas análises, o que não impede de extrapolarmos, com a devida cautela, seus resultados para outros países, especificamente o Brasil. Dentre outras desmistificações da retórica não condizente com a prática empregada pelos laboratórios farmacêuticos, ela desenvolve argumentos em torno dos seguintes pontos: 1- sigilo indesejável acerca da pesquisa, do marketing e dos preços; 2- preços demasiadamente altos e variáveis dos medicamentos; 3 produção em excesso dos chamados medicamentos de imitação, ao passo que os chamados medicamentos inovadores são insuficientes; 4- controle excessivo sobre os ensaios clínicos de seus próprios produtos; 5- forte influência sobre a educação médica a respeito dos seus próprios produtos; 6- longa duração das 
patentes e de outros direitos exclusivos de comercialização dos medicamentos; e 7- grande lobby frente à Food and Drug Administration (FDA).

Em certo sentido, o livro de Angell sintetiza vários estudos críticos que demonstram haver um grande controle por parte da indústria em relação aos demais atores do processo: cooptação dos médicos (amiúde empregam-se desde a velha tática de "dar presentes" até atitudes mais ousadas, como financiar participação em congressos); cooptação dos pesquisadores (os estudos, especialmente adstritos a medicamentos, costumam ser favoráveis aos interesses dos financiadores da própria pesquisa); cooptação das agências reguladoras (nessa esfera em particular, o lobby costuma ser bem incisivo, recorrendo inclusive ao "auxílio" de políticos); e cooptação do consumidor em geral (nesse caso, normalmente a grande estratégia empregada é a da propaganda, geralmente enganosa). Por essas e outras razóes, analisando o setor da saúde brasileiro e argentino, comparativamente ao norteamericano e europeu, Iriart (2008) propõe um novo papel (atuante e forte) para as agências reguladoras e para o Estado, inclusive no que diz respeito a um maior controle da publicidade.

Além das acusações citadas, outro tipo de problema que começou a ser atrelado às noções de CMI e CMF é o da medicalização social. Temática já clássica no contexto mais amplo da medicina social, o fato é que, geralmente, ela foi investigada por um viés crítico no sentido de "denuncista", seja alardeandose o poder excessivo exercido pelos médicos, seja desmascarando-se o controle assumido pelos planos e seguros de saúde.

Valendo-se de uma perspectiva mais ponderada, Conrad (2007) demonstra sua posição equilibrada sobre o assunto, a começar pela própria definição que ele propõe: "'Medicalização' descreve um processo pelo qual problemas não médicos tornam-se definidos e tratados como problemas médicos, usualmente em termos de doenças e desordens” (p.4).

Prosseguindo em sua análise, Conrad defende que a medicalização em si não é nem boa e nem ruim; pode ser positiva ou negativa, dependendo das circunstâncias. A questão persistente consiste em saber o liame entre a medicalização necessária e a super-medicalização. Por exemplo, a medicalização do alcoolismo acaba surtindo um efeito benéfico na superação do problema, ao passo que a recente medicalização da timidez nos EUA encontra resistência 
de vários segmentos da sociedade. Às vezes, a desmedicalização também pode propiciar um efeito liberalizador, como no caso do homossexualismo. Enfim, é preciso atentar para as particularidades de cada caso.

$\mathrm{Na}$ avaliação de Conrad, deve-se levar em consideração o papel relevante desempenhado por cada um dos vários atores envolvidos nesse processo social: médicos, movimentos sociais, organizações de pacientes, e pacientes potenciais enquanto consumidores. Seja como for, para o autor, a indústria farmacêutica passou a exercer uma função preponderante mais recentemente: ela passou a "falar" diretamente com o consumidor por intermédio do marketing; além disso, ela consegue atuar na redefinição de doenças já existentes e na criação de outras, na medida em que mantém uma irregular ascendência sobre as agências reguladoras. Camargo (2009) adverte que o papel dos interesses econômicos se expandiu a ponto de cobrir praticamente todo o processo de produção e difusão do conhecimento no campo biomédico, desde o financiamento de pesquisas à publicação de seus resultados, com efeitos nem sempre alinhados com os valores e interesses dos demais atores do campo, em especial dos usuários dos serviços de saúde.

Não se pode deixar de aludir que vem ganhando cada vez mais adeptos a perspectiva da chamada medicina alternativa complementar (MAC), u ma vez que costuma ser concebida como uma reação à medicalização social e, por extensão, ao complexo econômico da saúde. Isso porque essa modalidade de medicina consiste exatamente em práticas tradicionais tecnologicamente despojadas, com ênfase na prevenção e no tratamento, mais do que no diagnóstico. No contexto brasileiro, alguns autores defendem as MACs tendo como pressuposto justamente a superação de um paradigma epistemológico de matiz estritamente positivista (por exemplo: LUZ, 1996). Seja como for, autores como Conrad permanecem céticos quanto à possibilidade de as ditas práticas médicas alternativas contribuírem, efetivamente, para o processo de desmedicalização; o que ocorreria mais propriamente seria tão-somente uma "desprofissionalização" da medicina. Conrad nos lembra que o fato de a prática ser alternativa não significa necessariamente que seja menos medicalizante; acrescentaríamos, ainda, que, analogamente, essas práticas não seriam inerentemente "moralmente superiores", estando, portanto, acima e além do alcance dos inevitáveis conflitos de interesse entre aspectos econômicos e de atenção à saúde. 


\section{Conclusão}

Sem correr o risco de estarmos exagerando, a temática atinente ao complexo médico-industrial/financeiro deveria passar a ser vista como uma das mais relevantes no interior das discussões do campo da saúde coletiva, uma vez que ela envolve o setor saúde como um todo. Daí a necessidade de focarmos o problema sob novas perspectivas. Aqui, procuramos mostrar que os science studies podem servir como um referencial teórico promissor, desde que aparadas algumas arestas. Na verdade, eles podem funcionar como uma fonte inspiradora, a fim de que possamos abordar CMI/CMF levando em consideração toda a sua amplitude. De fato, torna-se cada vez mais necessário levar em conta tanto os interesses econômicos das indústrias farmacêutica e de equipamentos quanto os valores sociais e humanos dos que carecem da atenção à saúde, sem deixar de atentar, obviamente, para a atuação dos profissionais da saúde de um modo geral. Ademais, faz-se mister debruçarmo-nos sobre os aspectos epistemológicos e axiológicos que estão por trás de toda essa discussão. Isso porque há sempre, por um lado, uma concepção prévia de ciência e tecnologia - como também de como C\&T devem ser produzidas e difundidas -, e, por outro, uma pressuposição do que vêm a ser os valores em geral e de quais deles devem ser priorizados, ambos aspectos imperando - de modo nem sempre explicitado - no interior do complexo médico-industrial/financeiro. Cabe aos analistas, portanto, trazê-los à baila para que a discussão seja enriquecida.

Sem dúvida, o debate sobre o tema tornou-se progressivamente mais complexo, em parte pela própria complexificação do campo, que agregou mais agentes (p.ex.: o CMF), e que "explodiu” em termos de sua base tecnológica; mas em parte também pela trajetória política do país: a discussão inicial se deu num contexto de polarização sob o regime militar, e com o final deste, as posições políticas se matizam e não são facilmente enquadráveis a priori em um de dois campos antagônicos. Dessarte, a um objeto de análise por definição "complexo" deve corresponder um pensamento complexo ${ }^{24}$.

\section{Referências}

ANDREAZZI, M.; KORNIS, G. Padrōes de acumulação setorial: finanças e serviços nas transformações contemporâneas da saúde. Ciência \& Saúde Coletiva, v.13, n.5, p.14091420, 2008. 
ANGELL, M. The truth about the drug companies: how they deceive us and what to do about it. New York: Random House, 2005.

AVILA, J. O Desenvolvimento do Setor Farmacêutico: a Caminho de uma Estratégia Centrada na Inovação. Revista Brasileira de Inovação, v.3, n.2, jul/dez 2004.

BARNES, B. Scientific Knowledge and Sociological Theory. London: Routledge \& Kegan Paul, 1974.

BAUMGARTEN, M. (Org.). Conhecimentos e redes: sociedade, política e inovação. Porto Alegre: URFGS, 2005.

BLOOR, D. Knowledge and Social Imagery. 2. Ed. Chicago: University of Chicago Press, 1991. Ideals and monisms: recent criticisms of the Strong Programme in the sociology of knowledge. Stud. Hist. Phil. Sci., v.38, p.210-234, 2007.

BRAGA, J.; SILVA, P. A mercantilização admissível e as políticas públicas inadiáveis: estrutura e dinâmica do setor saúde no Brasil. In: NEGRI, B.; GIOVANNI, G. Brasil: radiografia da saúde. Campinas: UNICAMP, 2001.

BROWN, J. (Ed.). Scientific rationality: the sociological turn. Dordrecht, Holland: Reidel Press, 1984.

CAETANO, R.; VIANNA, C. Processo de Inovação Tecnológica em Saúde: uma análise a partir da organização industrial. Cadernos de Saúde Coletiva, v.14, n.1, p.95-112, 2006.

CAMARGO, K. Public health and the knowledge industry. Revista de Saúde Pública. São Paulo, v.43, p.1-6, 2009.

CARVAlHO, A.; CAMPOS, D.; BEVILACQUA, L. Science in Brazil. Rio de Janeiro: ABL, 2002.

CIMOLI, M. et al. Instituições e políticas moldando o desenvolvimento industrial: uma nota introdutória. Revista Brasileira de Inovação, v.6, n.1, p.55-85, jan/jun, 2007.

CONDE, M.; ARAÚJO-JORGE, T. Modelos e concepções de inovação: a transição de paradigmas, a reforma da C\&T brasileira e as concepçôes de gestores de uma instituição pública de pesquisa em saúde. Ciência \& Saúde Coletiva, v.8, n.3, p.727-741, 2003.

CONRAD, P. The Medicalization of Society: on the transformation of human conditions into treatable disorders. Baltimore: The Johns Hopkins University Press, 2007.

CORDEIRO, H. A indústria da saúde no Brasil. Rio de Janeiro: Graal, 1980.

DAGNINO, R.; DIAS, R. A política de C\&T brasileira: três alternativas de explicação e orientação. Revista Brasileira de Inovação, v.6, n.2, p.373-403, jul/dez 2007.

ETZKOWITZ, H.; LEYDESDORFF, L. The Triple Helix-University-IndustryGovernment relations: a laboratory for knowledge-based economic development. EASST Review, v.14, n.1, p.14-19, 1995. 
The dynamics of inovation: from National Systems and "Mode 2" to a Triple Helix of university-industry-government relations. Research Policy, v.29, 2000.

FEYERABEND, P. Science in a Free Society. London: Verso, 1978.

Farewell to reason. London: Verso, 1987.

. Conquest of abundance: a tale of abstraction versus the richness of being. Chicago:

University Chigago Press, 1999.

. Contra o método. São Paulo: UNESP, 2007.

FRIEDMAN, M. Reconsidering Logical Positivism. Cambridge: Cambridge University Press, 1999.

GADELHA, C. O complexo industrial da saúde e a necessidade de um enfoque dinâmico na economia da saúde. Ciência \& Saúde Coletiva, v.2, p.521-535, 2003.

. Desenvolvimento, complexo industrial da saúde e política industrial. Rev. Saúde Pública, v.40, (n. esp.), p.11-23, 2006.

GALISON, P. The many faces of big science. In: GALISON, P.; HEVLY, B. (Ed.). Big Science: the growth of large-scale research. Stanford, CA: Stanford University Press, 1992.

GIBBONS, M. et al. The New Production of Knowledge: the dynamics of science and research in contemporary societies. London: Sage, 1994.

IRIART, C. Capital financeiro versus complejo médico-industrial: los desafíos de las agencias regulatorias. Ciência \& Saúde Coletiva, v.13, n.5, p.1619-1626, 2008.

KREIMER, P. De Probetas, Computadoras y Ratones: la construcción de una mirada sociológica sobre la ciência. Buenos Aires: Universidad Nacional de Quilmes, 1999.

KRIMKY, S. Science in the private interest: has the lure of profits corrupted biomedical research? Lanham: Rowman \& Littefield, 2003.

KUHN, T. A Estrutura das Revoluções Científicas. 2. ed. São Paulo: Perspectiva, 1978.

. A Tensão Essencial. Lisboa: Edições 70, 1989.

The Road Since Structure: philosophical essays, 1970-1993, with an autobiographical interview. Chicago: University of Chicago Press, 2000.

LATOUR, B. Jamais fomos modernos: ensaio de antropologia simétrica. Rio de Janeiro: Ed 34, 1994.

A esperança de Pandora: ensaios sobre a realidade dos estudos científicos. São Paulo: EDUSC, 2001.

Políticas da Natureza: como fazer ciência na democracia. São Paulo: EDUSC, 2004.

LENOIR, T. Inventando a Universidade Empreendedora: Stanford e a co-evolução do Vale do Silício. In: REGNER, A.C.; ROHDEN, L. (Org.). A filosofia e a ciência redesenham horizontes. São Leopoldo: UNISINOS, 2005. 
LIANZA, S.; ADDOR, F. Tecnologia e desenvolvimento social e solidário. Porto Alegre: UFRGS, 2005.

LUZ, M. As Instituiçôes Médicas no Brasil. Rio de Janeiro: Graal, 1979.

. Racionalidades médicas e terapêuticas alternativas. Rio de Janeiro: IMS-UERJ, 1996. (Série Estudos em Saúde Coletiva, 62).

MENDONÇA, A. Por uma nova abordagem da interface ciência/sociedade: a tarefa da filosofia da ciência no contexto dos science studies. 239f. Tese (Doutorado em Filosofia) Universidade do Estado do Rio de Janeiro, Rio de Janeiro, 2008.

MENDONÇA, A.; VIDEIRA, A. Instituindo os science studies. Episteme, Porto Alegre, n.19, p.149-158, jul./dez. 2004.

MENDONÇA, A.; ARAÚJO, P.; VIDEIRA, A. Primazia da democracia e autonomia da ciência: o pensamento de Feyerabend no contexto dos science studies. Filosofia Unisinos, v.11, n.1, p.44-61, jan/abr 2010.

NEGRI, B.; GIOVANNI, G. Brasil: radiografia da saúde. Campinas: UNICAMP. IE, 2001.

NICKLES, T. Philosophy of science and history of science. OSIRIS, v.10, p.139-163, 1995.

NOWOTNY, H.; SCOTT, P.; GIBBONS, M. Re-Thinking Science: knowledge and the public in an age of uncertainty. Cambridge: Polity Press, 2001.

POLANYI, M. The Republic of Science: its political and economic theory. Minerva, n.38, p.1-32, 2000.

ROUSE, J. Engaging Science: how to understand its practices philosophically. Ithaca: Cornell University Press, 1996.

How Scientific Practices Matter: reclaiming philosophical naturalism. Chicago: University of Chicago Press, 2002.

SANTOS, B. (Org.). Conhecimento Prudente para uma Vida Decente. 'Um Discurso sobre as Ciências' revisitado. 2. ed. São Paulo: Cortez, 2006.

SHINN, T. Regimes de produção e difusão de ciência: rumo a uma organização transversal do conhecimento. Scientiae Studia, v.6, n.1, p.11-42, 2008.

STARR, P. The social transformation of American medicine. New York: Basic Books, 1982.

TOSH, N. Science, truth, and history, Part I. Historiography, relativism and the sociology of scientific knowledge. Stud. Hist. Phil. Sci., v.37, n.4, p.675-701, 2006.

VIANNA, C. Política tecnológica e evolução industrial no setor da saúde. In: GUIMARÃES, R.; TAVARES, R. Saúde e Sociedade no Brasil. Anos 80. Rio de Janeiro: Relume Dumará, 1994.

Estruturas do sistema de saúde: do complexo médico-industrial ao médicofinanceiro. PHYSIS: Rev. Saúde Coletiva, Rio de Janeiro, v.12, n.2, p.375-390, 2002. 
VIDEIRA, A. A Filosofia da ciência sob o signo dos science studies. Abstracta, v.2, n.1, p.70-83, 2005.

Historiografia e história da ciência. Escritos, v.1, n.1, p.111-158, 2007.

\section{Notas}

${ }^{1}$ Conquanto já se utilize a expressão portuguesa "estudos científicos", optamos, aqui, por empregar a expressão original, dado que, mesmo em solo não anglo-saxão, ela costuma ser mantida. Para uma apresentação dos science studies no contexto nacional, nós referimos os trabalhos de Videira (2005; 2007); Mendonça e Videira (2004); e Mendonça, Araújo e Videira (2010), uma reavaliação do pensamento de Feyerabend em comparação ao referencial dos science studies.

2 Sendo um dos representantes mais importantes do movimento de retorno ao positivismo lógico, Friedman (1999) procura mostrar que não teria havido, propriamente falando, uma ruptura da tradição considerada pós-positivista em relação aos seus precursores: Kuhn e seus colegas de geração estariam muito mais próximos de Carnap e dos demais membros do Círculo de Viena do que geralmente se supõe, uma vez que os positivistas lógicos também não seriam empiristas ingênuos, como costumam ser rotulados pela interpretação corrente.

${ }^{3}$ Podemos dizer, sem corrermos o risco de estarmos exagerando, que a tese da incomensurabilidade pautou a agenda da filosofia da ciência dita pós-kuhniana até bem recentemente. Em certo sentido, ela continua sendo um tema relevante, embora não seja mais necessariamente identificada como uma ameaça à racionalidade cientifica.

${ }^{4} \mathrm{O}$ locus classicus da discussão sobre a suposta cientificidade do programa forte é Brown (1984).

${ }^{5}$ Para uma maior elucidação do desenvolvimento histórico da sociologia da ciência, ver Kreimer (1999).

${ }^{6}$ Nickles (1995) e Tosh (2006) chamaram a atenção para outra incongruência dos science studies: parte-se do pressuposto de que o conhecimento científico é sempre situado no tempo e no espaço, mas, em seguida, produzem-se análises que pretendem transcender a todo e qualquer tipo de condicionamento contextual. Por isso, cada um ao seu modo, Nickles e Tosh sugerem que, para serem coerentes, os science studies precisam admitir um olhar histórico guiado pela visão da ciência do presente; se é que eles não o fazem ao menos na prática.

${ }^{7}$ Do final dos anos 1980 para cá, Latour e seus colegas têm procurado evitar o emprego da expressão construção social, de modo a não serem confundidos com os construtivistas radicais. Eles visam encontrar, por razões diferentes, uma posição intermediária entre o realismo (ingênuo) clássico e o anti-realismo do construtivismo social.

${ }^{8}$ Para muitos autores, os science studies seriam os grandes responsáveis contemporâneos por novas batalhas nas chamadas guerras das ciências, o que não parece ser uma interpretação muito fidedigna dos fatos. Ao menos Latour e seus colegas de campo estão longe de ser inimigos da ciência. Para mais um "capítulo" interessante das referidas guerras, ver Santos (2006).

${ }^{9}$ Rouse $(1996$; 2002) pretende ser uma exceção à regra, embora suas formulações ainda careçam de uma maior consistência.

${ }^{10}$ A ser correta a afirmação de Starr (1982), a expressão já estaria em uso pelo menos desde o início dos anos 1970.

${ }^{11}$ A expressão "complexo industrial-militar" foi primeiro empregada, em tom de denúncia, pelo então presidente americano, Dwight D. Eisenhower, em seu discurso de despedida como presidente em 1961. Cf. http://www.h-net.org/-hst306/documents/indust.html. [Consultado em 12 de maio de 2010] 
${ }^{12}$ Para uma história deste enfrentamento até (e durante) o regime militar, ver, por exemplo, Luz (1979).

${ }^{13}$ Aliás, em parceria com Caetano, Vianna (2006) empreende uma análise sobre a organização industrial da saúde a partir do contexto da ciência e tecnologia, atendo-se mais especificamente à noção de inovação. Análise esta, segundo os autores, imprescindível para deslindar as transformações que a saúde vem sofrendo ao longo dos anos, bem como para uma melhor gestão e avaliação do setor.

${ }^{14}$ Avila (2004) desenvolve um argumento e uma proposta similares aos de Gadelha.

${ }^{15}$ Procurando estar afinado com as políticas científicas do restante do mundo, o MCT está dando cada vez mais ênfase à questão da inovação, a ponto de em seus documentos oficiais aparecer, recorrentemente, a tríade "Ciência, Tecnologia \& Inovação" (CT\&I), em lugar do binômio "Ciência \& Tecnologia” (C\&T).

${ }^{16}$ Embora já desatualizado, um bom diagnóstico sobre a situação das ciências da saúde e das ciências biomédicas no Brasil, em termos de produção de conhecimento e de tecnologia e inovação, é fornecido no trabalho de Carvalho, Campos e Bevilacqua (2002), especificamente nos capítulos 3 e 9.

${ }^{17}$ De modo a responder ou rebater a tantas críticas e a desfazer o que seriam mal-entendidos de compreensão, alguns dos autores do primeiro livro publicaram um segundo denominado Re-Thinking Science: Knowledge and the Public in an Age of Uncertainty.

${ }^{18}$ Trata-se de um dos temas mais espinhosos do nosso tempo - o da mercantilização da ciência. A literatura sobre o assunto já é tão extensa que acaba dificultando a indicação dos trabalhos mais importantes. De qualquer modo, a obra do físico e analista da ciência John Ziman - que, inclusive, manteve uma polêmica interessante com Michael Gibbons - pode ser uma excelente porta de entrada para o "cômodo" mais filosófico da questão. Referente ao contexto específico da saúde, Krimsky (2003) desenvolve o argumento de que as indústrias farmacêuticas podem estar engendrando um desvio dos ideais humanitários da pesquisa e prática médicas.

${ }^{19}$ Dentre as deficiências e inconsistências apontadas pelos críticos, vale a pena mencionar as seguintes: as análises empreendidas pelos autores ainda seriam muito generalistas, carecendo de estudos de caso mais concretos; ao contrário do que eles sustentam, o "Modo 2" é que seria mais recorrente historicamente, enquanto o "Modo 1" seria uma "invenção" recente; apesar da "fala" sobre contexto de aplicação, pouco espaço seria dado à participação pública no processo de produção do conhecimento ou ao chamado contexto de implicação; e, por fim, a crítica de que os autores reificam ou naturalizam as relações entre ciência e sociedade, como se ambas não fossem frutos de um processo político e social mais amplo.

${ }^{20}$ Começa a ser divulgado no Brasil, cada vez mais, o chamado modelo transversal de produção e difusão do conhecimento proposto por Terry Shinn. Ver, por exemplo, Shinn (2008).

${ }^{21}$ A Editora Unicamp vem publicando grande parte desses trabalhos na coleção "Clássicos da Inovação".

${ }^{22}$ Uma análise interessante sobre os sistemas nacionais de inovação como políticas públicas, no contexto dos países da OCDE em geral, e em particular do Brasil, foi empreendida por Cassiolato e Lastres (2000). Para uma análise mais crítica da atual política brasileira de CT\&I, ver Dagnino e Dias (2007).

${ }^{23} \mathrm{O}$ estudo específico de Conde e Araújo-Jorge incidiu sobre a visão de inovação dos gestores da Fundação Oswaldo Cruz.

${ }^{24}$ A.L.O. Mendonça participou da redação do artigo, da análise e da coleta de dados. K.R.de Camargo Jr participou da redação do artigo e da análise de dados. 


\section{Medical-industrial and medical-financial complex: the epistemological and axiological sides of the balance}

In this paper we present an analysis of the issues concerning the medical-industrial complex (MIC) and medical-financial complex (MFC), inspired by the theoretical framework of the science studies. The discussion about the medical-industrial/financial complex is approached under the aegis of a dychotomic split between economic interests and social values. We intend to draw attention to the need to consider the different angles of the issue, since the mentioned notions seek to nominate a very complex type of phenomenon. In order to attain an evaluation of the problem that is at once broad and deep, we consider necessary to unearth the underlying ideas to both its epistemological and axiological aspects as well. In order to achieve this goal, we begin with a brief contextualization and reassessment of the science studies; this is followed by an equally brief review of the available literature in Portuguese pertaining to the concepts of MIF and MFC, emphasizing the recent attempts to surpass the dychotomy "economic interests versus social values"; after that we attempt to elucidate, based upon the discussion about different modes of knowledge production, the epistemological and economic background underlying the MIC; after that, we bring to the forefront some critical diagnoses of the pharmaceutical industry, drawing on the notions of social medicalization and complementary $\&$ alternative medicine (CAM); finally, we point towards an approach as broad and acute possible of a problematic that can no longer be thought of in dychotomic terms.

> Key words: medical-industrial complex; medical-financial complex; economic interests; social values; epistemology; axiology; science studies. 